\title{
Time course of the rabbit's conditioned nictitating membrane movements during acquisition, extinction, and reacquisition
}

\author{
E. James Kehoe, ${ }^{1}$ Elliot A. Ludvig, ${ }^{2}$ and Richard S. Sutton ${ }^{3}$ \\ ${ }^{1}$ School of Psychology, University of New South Wales, Sydney 2052, Australia; ${ }^{2}$ Department of Psychology, University of Warwick, \\ Coventry CV4 7AL, United Kingdom; ${ }^{3}$ Department of Computing Sciences, University of Alberta, Edmonton T6G 2E8, Canada
}

\begin{abstract}
The present experiment tested whether or not the time course of a conditioned eyeblink response, particularly its duration, would expand and contract, as the magnitude of the conditioned response (CR) changed massively during acquisition, extinction, and reacquisition. The CR duration remained largely constant throughout the experiment, while CR onset and peak time occurred slightly later during extinction. The results suggest that computational models can account for these results by using two layers of plasticity conforming to the sequence of synapses in the cerebellar pathways that mediate eyeblink conditioning.
\end{abstract}

Computational models of eyeblink conditioning generally predict that, during the pairings of a conditioned stimulus (CS) with the unconditioned stimulus (US), the conditioned response (CR) should expand in magnitude and duration around the point of US delivery. Thus, during acquisition, the CR should roughly resemble the changes in the height and width of the sun's rising across the horizon, as depicted schematically in the top panel of Figure 1. Conversely, during the successive CS-alone presentations in extinction, the CR should contract like a setting sun.

These predictions flow from the shared assumption that the CS onset initiates a spectrum of microstimuli, whose intensities increase and decrease at different rates (Desmond and Moore 1988; Grossberg and Schmajuk 1989; Machado 1997; Ludvig et al. 2012). At a neural level, the spectrum of microstimuli appears to start with the projection of mossy fibers into the cerebellar cortex (Buonomano and Mauk 1994; Moore and Choi 1997; Mauk et al. 2000; Lepora et al. 2010). In turn, these mossy fiber inputs are refined as temporal codes by interactions among Golgi and granule cells that are active at different times (Kalmbach et al. 2011). Experimentally, asynchronous stimulation of two populations of mossy fibers can act as a CS for acquisition of welltimed eyeblink CRs in rabbits, and post-acquisition manipulations of the relative stimulus durations can predictably alter the CR timing (Kalmbach et al. 2011). In turn, the outputs of these cells activate parallel fibers that converge near the base of Purkinje cells. As a result of pairing stimulation of these microstimulus-like pathways with stimulation of ascending US pathways, CR-like activity has, in fact, been observed in individual Purkinje cells (Jirenhed et al. 2007; Jirenhed and Hesslow 2011).

According to the behavioral and neural models described above, each microstimulus gains associative strength in proportion to its level of activation during the US. Thus, the microstimulus whose maximum intensity occurs during the US will gain the greatest associative strength, although microstimuli that are weaker at the time of US will gain less associative strength. During subsequent CS presentations, the magnitude of a CR at any point in time reflects the sum of the associative strengths of the microstimuli multiplied by their level of activity at that moment.

\footnotetext{
Corresponding author: j.kehoe@unsw.edu.au, ejameskehoe@ gmail.com

Article is online at http://www.learnmem.org/cgi/doi/10.1101/Im.034504.114.
}

Hence, a CR's peak occurs near the time of US delivery, although the CR will be smaller at earlier or later times.

The location of the CR's peak near the US is well documented for acquisition and extinction in eyeblink conditioning (Smith 1968; Kehoe and Joscelyne 2005). Regarding the duration of the CR, only its starting point, expressed as the CR onset latency, has been examined extensively. However, as the technology has switched from subjective judgments of analog waveforms to algorithmic computations on digitized waveforms (Marshall-Goodell et al. 1982), findings concerning changes in the onset latency over trials have become less certain and less supportive of spectral timing models. Analog judgments have indicated that, consistent with spectral models, the onset latency becomes shorter as the CR grows in rabbits (Schneiderman and Gormezano 1964; Gormezano et al. 1983), but also rats (Hughes and Schlosberg 1938), dogs (Hilgard and Marquis 1935), and monkeys (Hilgard and Marquis 1936). More recent algorithmic computations, however, have suggested otherwise. A recent trial-by-trial analysis revealed that, for a 500-msec CS in delay conditioning, the onset latencies in rabbits appeared stable across acquisition (Kehoe et al. 2008), although subject to cycles of within-session increases and between-session recovery (Ohyama et al. 2010). For ISIs $>500$ msec in delay conditioning, the CR onset latency tends to lengthen, rather than shorten, across sessions (Kehoe and Schreurs 1986; Vogel et al. 2003) as well as within sessions (Ohyama et al. 2010). For ISIs $<500 \mathrm{msec}$, the CR onset latency remains short (Kehoe and Schreurs 1986) or becomes shorter (Vogel et al. 2003).

Whether extinction involves a reduction in excitatory strengths or the acquisition of countervailing inhibitory strengths attached to the microstimuli, the CR onset latency should increase as the CR contracts. The available data for eyeblink conditioning are limited. In both delay and trace conditioning of the rabbit, even analog recordings suggest that the CR onset latency largely remains constant, perhaps decreasing slightly, rather than increasing (Schneiderman and Gormezano 1964; Smith 1968).

(C) 2014 Kehoe et al. This article is distributed exclusively by Cold Spring Harbor Laboratory Press for the first 12 months after the full-issue publication date (see http://learnmem.cshlp.org/site/misc/terms.xhtml). After 12 months, it is available under a Creative Commons License (AttributionNonCommercial 4.0 International), as described at http://creativecommons. org/licenses/by-nc/4.0/. 


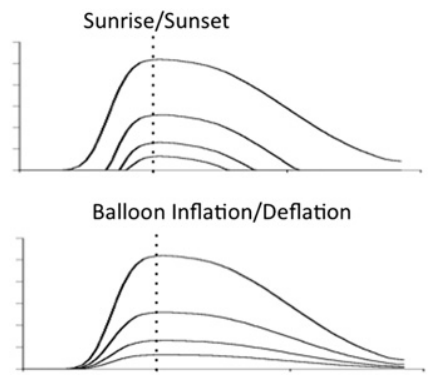

Figure 1. Schematic depictions of the sunset/sunrise model in which the CR duration and magnitude are proportional (top panel) and the inflation/deflation model in which the CR duration is constant (bottom panel).

Together, these findings suggest that the time course of the CR in acquisition and extinction may be as depicted in the bottom panel of Figure 1, which resembles the inflation or deflation along the length of a balloon. This pattern can explain the divergence between the subjective and algorithmic methods. Ideally, both methods locate the CR onset at the point when the eyelid closure exceeds a minimum criterion (Marshall-Goodell et al. 1982). However, with the subjective method, locating the starting point of early CRs, which have gradual slopes, is difficult relative to later CRs, which have more pronounced slopes. This explanation, it should be noted, does not rule out the sunrise/sunset pattern. Mechanical lags and variability in the response system in the pathways mediating the eyelid movement could also produce more gradual slopes for small movements (Lepora et al. 2007, 2009; Mavritsaki et al. 2007).

In order to ascertain which pattern prevails, the present study examined the acquisition, extinction, and reacquisition of CRs. On one hand, the sunrise/sunset model predicts that, when response magnitude increases in acquisition and reacquisition, the entire CR should expand: (1) the onset latency should decrease, (2) the offset latency should increase, and (3) thus the duration should increase. When response magnitude decreases in extinction, the CR should contract: the onset latency should increase, offset latency should decrease, and duration should decrease. On the other hand, the balloon inflation/deflation model predicts that response onset latency, offset latency, and duration should all remain constant, whether response magnitude increases or decreases. Some of the acquisition data have previously been reported (Kehoe et al. 2008).
Three groups of rabbits ( $n=8$ ) were given $16 \mathrm{~d}$ of acquisition training, each containing 60 presentations of a CS followed at its offset by a US on either $90 \%, 70 \%$, or $50 \%$ of the trials using apparatus and procedures detailed previously (Gormezano 1966; Kehoe and Joscelyne 2005). (One rabbit in the 90\% condition was lost to illness.) The CS was a $500-$ msec tone $(1000 \mathrm{~Hz}, 83-\mathrm{dB}$ SPL, C scale superimposed on a 76-dB background), and the US was a 50-msec, 3-mA, 50- Hz AC current to the periorbital region. All rabbits were then given $6 \mathrm{~d}$ of extinction training, each containing $60 \mathrm{CS}$-alone presentations, and then $3 \mathrm{~d}$ of reacquisition training, in which $90 \%$ of the CS presentations were paired with the US.

Differences among means were tested using a multivariate method (O'Brien and Kaiser 1985). Effect sizes were expressed as the lower and upper limits of the 95\% confidence interval for the difference $(d)$ in standard deviation units (Cohen 1988; Bird 2004).

Figure 2 shows the time course of CRs constructed by averaging the momentary NM readings for all rabbits at successive 5-msec time points after CS onset on CS-alone trials within each of the specified days in each phase. As a fine-grain representation of the timing and magnitude data, left-hand side panels in Figure 3 combine each animal's trial-by-trial measurements (small dotlike circles) and mean for each block of six CS-alone trials (larger circles) across the three phases.

The CR's magnitude became progressively larger across acquisition sessions. As reported previously for these data (Kehoe et al. 2008), there were initial differences related to the proportion of CS-US trials, but by the last day of acquisition, CR magnitudes across groups had converged on mean levels $\sim 2.10 \mathrm{~mm}$ $(\mathrm{SEM}=0.25 \mathrm{~mm}), F_{(1,20)}=2.21, P>0.10$. Thereafter, any apparent differences among the groups were small and not statistically significant. Consequently, the data from the three groups were amalgamated.

As previously found for extinction (Napier et al. 1992; Kehoe 2006), the CR declined both within sessions, linear-trend $F_{(1,20)}=$ $51.77, P<0.01, d(0.697,1.266)$ and across sessions of extinction, linear-trend $F_{(1,20)}=36.76, P<0.01, d(0.611,1.253)$. Finally, within the first day reacquisition training, CRs rapidly reached magnitudes $40 \%$ higher than on the last day of acquisition, $F_{(1,20)}=13.92, P<0.01, d(0.28,0.98)$. Thereafter, CR magnitudes fluctuated only slightly, linear-trend $F<1$.

Despite large changes in magnitude, the timing of the CR peak and duration appeared to change very little. To provide a picture without averaging artifacts, four temporal features of each
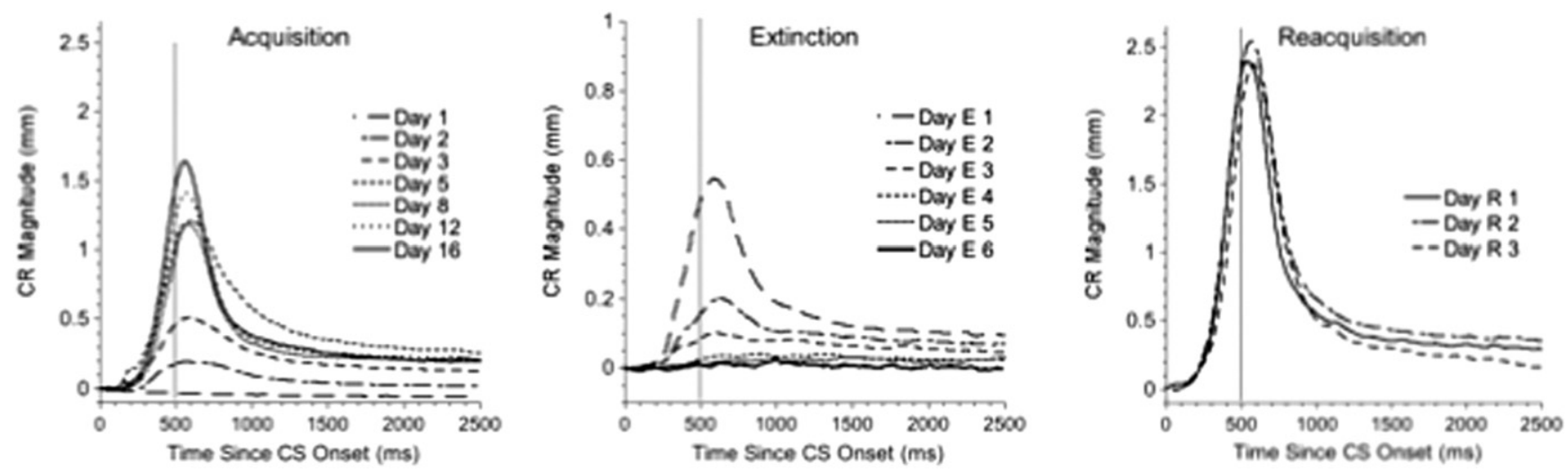

Figure 2. The time course of CRs constructed by averaging the momentary NM readings for all rabbits at successive 5-msec time points after CS onset on CS-alone trials within each of the specified days in each phase. Note that the $y$-axis for the extinction phase has been adjusted to more clearly expose the decline in overall magnitude over days. The time of US onset on CS-US trials is marked by the vertical line at the 500-msec point. 

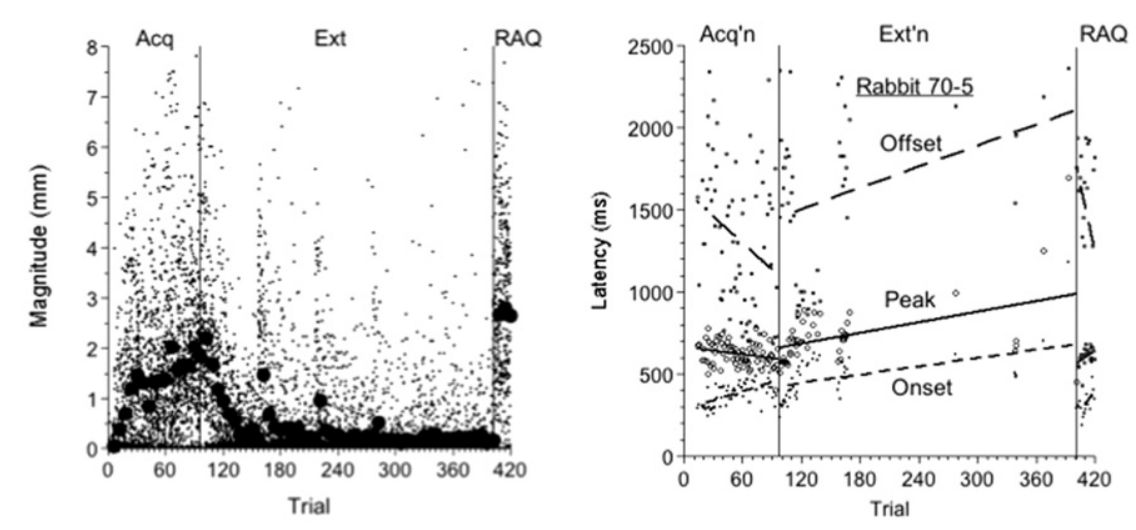

the end of the CS. To illustrate the range of these fits, the right-hand side panels in Figure 3 plot the fits for three representative rabbits selected on the basis that, for onset latency in acquisition, they showed, respectively, the largest increase (Rabbit 70-5), the median change (Rabbit 50-8), and largest decrease (Rabbit 50-2).

Table 1 shows the individual beta weights (slopes) for the fitted line expressed as msec/trial. To maintain an equivalent expression of slope across phases, all regressions were conducted using the absolute number of the CSalone trial in the complete sequence of trials. For example, in reacquisition, ev-
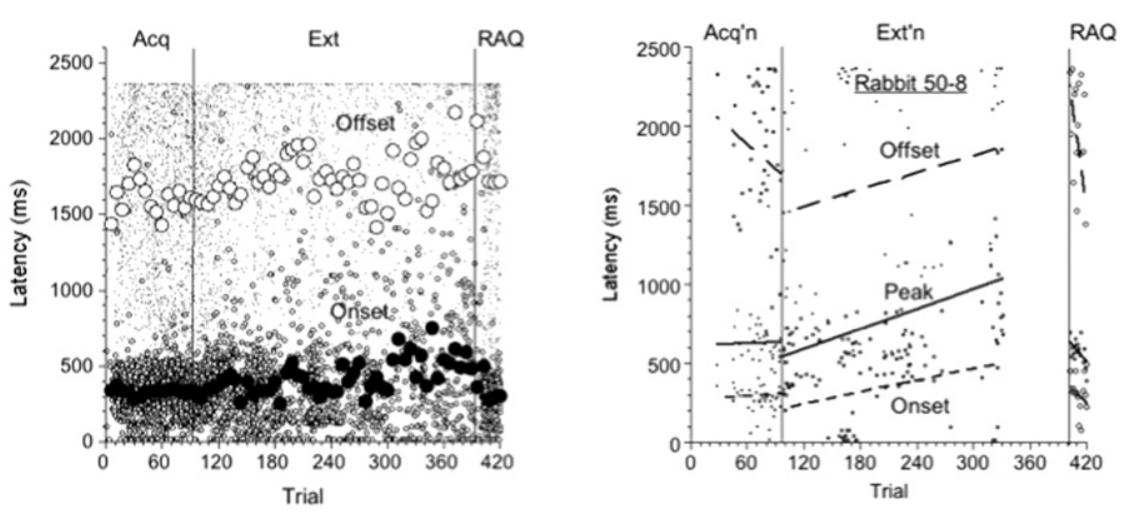
ery 10th trial was a CS-alone trial, and, accordingly, their values were entered as 10, 20, etc. In Table 1, the beta weights highlighted in bold indicate regressions that explained $10 \%$ or more of the variance. The mean of the slopes across all rabbits was tested against a hypothesized mean of zero using a two-tailed, onesample $t$-test.

Figure 3 reveals that, in acquisition, the large changes in response magnitude were accompanied by small changes in CR timing. Table 1 indicates that the slopes for the onset latency were generally small and their average was near zero $(P=$ $0.66)$. The slopes for duration and concurrently offset latency tended to be
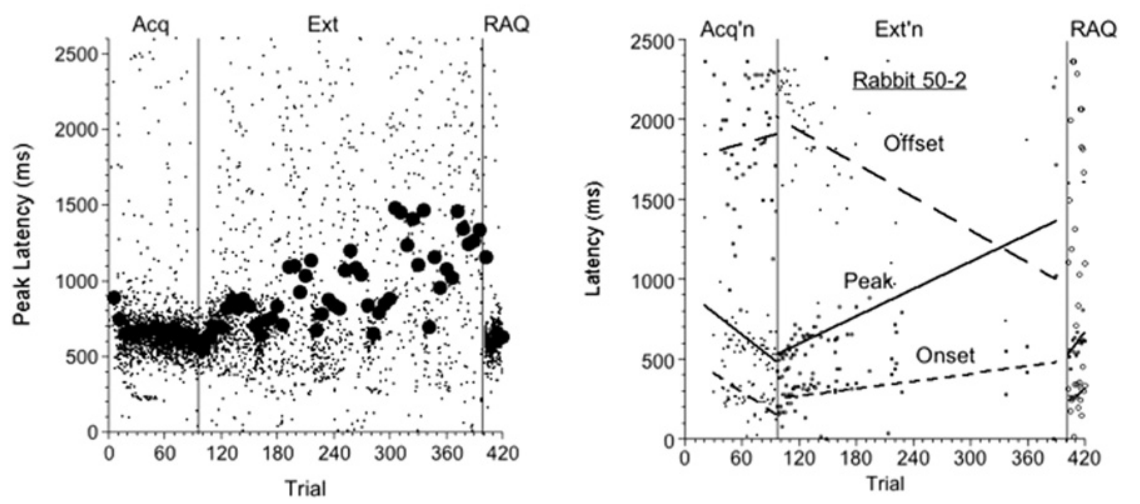
negative, meaning that, across acquisition, the CR contracted as magnitude increased. The mean beta weight for duration was negative, indicating a contraction, but this contraction differed statistically from zero only by using an unprotected Type I error of $0.05\left(P^{\prime} \mathrm{s}=\right.$ 0.04). Peak latency also decreased, but not significantly $(P=0.17)$.

In extinction, the magnitude measures plotted in Figure 3 indicate that most responding occurred on the first day, with only brief periods of spontaneous recovery subsequently (Napier et al. 1992; Kehoe 2006). Thus, linear regressions were conducted for both the first day alone and all $6 \mathrm{~d}$. The lower portion of Table 1 indicates that, across both sets of regressions, the onset latency showed a significant increase across trials $(P$ 's $<0.001)$. Offset latency also showed an increase, which was accompanied by

3. On the left-hand side, each panel shows each animal's trial-by-trial measurements dot-like circles) and overall mean for each block of 6 CS-alone presentations (larger circles) during acquisition (Acq), extinction (Ext), and reacquisition (RAQ). (Top) The maximum magnitude of closure by the rabbit's nictitating membrane (NM), including zero movements. (Middle) Both the onset and offset latencies. (Bottom) "Peak latency," the time of the NM maximum closure. On the right-hand side, each panel shows for one rabbit its individual data points and linear fits for onset latencies (short-dash line), peak latencies (solid line), and offset latencies (long-dash line).

rabbit's CRs in each phase were fitted using linear regression. These were: (1) "onset latency," defined as the time point at which the closure reached $0.165 \mathrm{~mm}$ above a pre-CS baseline; (2) "duration," defined as the interval between CR onset and CR offset; (3) "offset latency," defined as the last time point at which the closure declined below a criterion of $0.165 \mathrm{~mm}$ above a post-CS baseline; and (4) "peak latency," defined as the time point at which any closure exceeding the $0.165-\mathrm{mm}$ criterion above the pre-CS baseline reached its maximum. The pre-CS baseline was computed over a 200-msec interval before CS onset, and the post-CS baseline was computed over a 200-msec interval starting $1860 \mathrm{msec}$ after considerable variance. Only the increase across all days was statistically significant $(P=0.014)$. Whereas onset and offset latencies were increasing, duration did not appear to reliably increase or decrease across extinction. Finally, the peak latency showed a significant increase $\left(P^{\prime} \mathrm{s}<0.001\right)$. In reacquisition, all the timing measures rapidly returned to their values at the end of acquisition ( $P$ 's $>0.20$ for trends across days.).

For purposes of refining computational models, the present results appear more consistent with the balloon model for the time course of the CR sketched in the bottom panel of Figure 1. Although response magnitude increased, decreased, 
Table 1. Slopes of best-fitting lines (milliseconds/trial)

\begin{tabular}{|c|c|c|c|c|c|c|c|c|}
\hline \multirow[b]{2}{*}{ Group-rabbit } & \multicolumn{4}{|c|}{ Acquisition } & \multicolumn{4}{|c|}{ Reacquisition } \\
\hline & Onset & Duration & Offset & Peak & Onset & Duration & Offset & Peak \\
\hline $90-1$ & -0.01 & -0.63 & -0.64 & -0.41 & 0.88 & -3.09 & -2.21 & -0.03 \\
\hline $90-2$ & 0.05 & 0.19 & 0.23 & 0.06 & 0.39 & 0.48 & 0.87 & -0.11 \\
\hline $90-3$ & 0.1 & 0.21 & 0.32 & 0 & 0.25 & -3.92 & -3.67 & -0.14 \\
\hline $90-4$ & -0.03 & -0.13 & -0.16 & -0.11 & 0.54 & 1.88 & 2.42 & 0.04 \\
\hline $90-5$ & -0.02 & -0.73 & -0.76 & -0.06 & -0.23 & -4.14 & -4.37 & -0.06 \\
\hline $90-6$ & 0.1 & -0.77 & -0.67 & -0.35 & -0.36 & -1.58 & -1.94 & 0.52 \\
\hline $90-7$ & 0.08 & 0.13 & 0.22 & 0.16 & 0.48 & 0.65 & 1.12 & 0.3 \\
\hline $70-1$ & -0.08 & -0.27 & -0.35 & -0.18 & -0.46 & 1.96 & 1.49 & 0.01 \\
\hline $70-2$ & -0.08 & -0.26 & -0.34 & 0.04 & -0.12 & 2.2 & 2.09 & 0.05 \\
\hline $70-3$ & -0.1 & 0.13 & 0.02 & -0.28 & 0.02 & 0.93 & 0.95 & 0.35 \\
\hline $70-4$ & 0.03 & -0.1 & -0.07 & -0.05 & 0.61 & 0.49 & 1.1 & -1.26 \\
\hline $70-5$ & 0.18 & -0.71 & -0.53 & -0.08 & 0.76 & -3.53 & -2.77 & 0.41 \\
\hline $70-6$ & 0.08 & -0.8 & -0.72 & 0.11 & -0.22 & -0.01 & -0.23 & 0.72 \\
\hline $70-7$ & 0.1 & -0.53 & -0.43 & -0.12 & 0.19 & 6.82 & 7.01 & 0.51 \\
\hline $70-8$ & 0.13 & 0.37 & 0.51 & -0.05 & 0.24 & -1.76 & -1.52 & 2.68 \\
\hline $50-1$ & 0.06 & -0.06 & 0 & -1.68 & 0.78 & 4.99 & 5.77 & 1.01 \\
\hline $50-2$ & -0.42 & 0.56 & 0.13 & -0.51 & 0.58 & -0.54 & 0.04 & 0.84 \\
\hline $50-3$ & -0.02 & -0.39 & -0.4 & 0.2 & -0.29 & 1.09 & 0.8 & 0.54 \\
\hline $50-4$ & 0.13 & -0.49 & -0.36 & 0.73 & 0.19 & -0.42 & -0.23 & 0.74 \\
\hline $50-5$ & 0.04 & -1.29 & -1.25 & -0.12 & 0.54 & 2.83 & $\mathbf{3 . 3 7}$ & 3.49 \\
\hline $50-6$ & 0.05 & 0.57 & 0.62 & 0.17 & 0.38 & 1.12 & 1.5 & 0.51 \\
\hline $50-7$ & -0.14 & 0.36 & 0.22 & -0.41 & -0.79 & -1.13 & -1.93 & 3.55 \\
\hline $50-8$ & 0.04 & -0.56 & -0.52 & 0.02 & -0.63 & $-\mathbf{3 . 8 7}$ & -4.5 & -0.76 \\
\hline Mean & 0.01 & -0.23 & -0.21 & -0.13 & 0.16 & 0.06 & 0.22 & 0.6 \\
\hline SD & 0.12 & 0.49 & 0.46 & 0.43 & 0.47 & 2.8 & 2.92 & 1.17 \\
\hline \multirow[t]{2}{*}{$P$} & 0.66 & 0.04 & 0.04 & 0.17 & 0.11 & 0.92 & 0.72 & 0.02 \\
\hline & \multicolumn{4}{|c|}{ Extinction Day 1} & \multicolumn{4}{|c|}{ Extinction-all } \\
\hline Group-rabbit & Onset & Duration & Offset & Peak & Onset & Duration & Offset & Peak \\
\hline $90-1$ & 4.44 & 3.39 & 7.83 & 10.73 & 1.37 & -0.37 & 1 & 2.32 \\
\hline $90-2$ & 0.59 & -15.74 & -15.15 & 5.26 & 0.03 & 0.88 & 0.91 & 1.9 \\
\hline $90-\overline{3}$ & 3.02 & 14.62 & 17.64 & 6.67 & 0.86 & $\mathbf{3 . 3 5}$ & 4.21 & 6.49 \\
\hline $90-4$ & 0.29 & -2.97 & -2.68 & 0.98 & 0.65 & -0.67 & -0.02 & 1 \\
\hline $90-5$ & 4.75 & -9.9 & -5.15 & 8.36 & 0.35 & -2.43 & -2.09 & -0.04 \\
\hline $90-6$ & 18.23 & -14.09 & 4.14 & 15.39 & 1.69 & 0.14 & 1.83 & 2.74 \\
\hline $90-7$ & 11.9 & -24.02 & -12.13 & 11.17 & -0.18 & -1.29 & -1.46 & -0.25 \\
\hline $70-1$ & 1.8 & 2.37 & 4.17 & 8.75 & -0.53 & 0.66 & 0.13 & 5.04 \\
\hline $70-2$ & 5.01 & 22.03 & 27.04 & 3.28 & 0.3 & 4.49 & 4.79 & 6.71 \\
\hline $70-3$ & 5.82 & -8.19 & -2.37 & 33.16 & 1.9 & -1.94 & -0.04 & 2.9 \\
\hline $70-4$ & 3.68 & 10.66 & 14.34 & 16.5 & 1.58 & 1.06 & 2.64 & 4.99 \\
\hline $70-5$ & 9.43 & -40.23 & -30.8 & 7.54 & 0.85 & 1.3 & 2.15 & 1.08 \\
\hline $70-6$ & 2.97 & 12.01 & 14.98 & 34.03 & 0.24 & 4.75 & 4.99 & 9.58 \\
\hline $70-7$ & 0.16 & 7.25 & 7.41 & -0.67 & -0.42 & 2.89 & 2.47 & 1.93 \\
\hline $70-8$ & 10.39 & 7.03 & 17.42 & 13.5 & 0.24 & 2.54 & 2.78 & 5.23 \\
\hline $50-1$ & 2.12 & 10.77 & 12.9 & 5.43 & 2.55 & -1.75 & 0.8 & 4.68 \\
\hline $50-2$ & 2.36 & -14.74 & -12.38 & 15.88 & 1.31 & -3.65 & -2.34 & 4.7 \\
\hline $50-3$ & -0.27 & -6.3 & -6.56 & -2.42 & 0.81 & -4.71 & -3.9 & 0.51 \\
\hline $50-4$ & 14.74 & -40.16 & -25.42 & 15.26 & 0.77 & 4.18 & 4.95 & 10.91 \\
\hline $50-5$ & 17.45 & 14.51 & 31.95 & 32.65 & 2.12 & 1.6 & 3.72 & 9.32 \\
\hline $50-6$ & 8.56 & -12.66 & -4.11 & 38.67 & 0.97 & -1.03 & -0.06 & 1.96 \\
\hline $50-7$ & 0.82 & -0.49 & 0.33 & 0.72 & -0.52 & 1.9 & 1.39 & 2.26 \\
\hline $50-8$ & -1.3 & -16.85 & -18.15 & 2.64 & 1.25 & 0.52 & 1.77 & 2.14 \\
\hline Mean & 5.52 & -4.42 & 1.1 & 12.33 & 0.79 & 0.54 & 1.33 & 3.83 \\
\hline SD & 5.7 & 16.63 & 16.01 & 11.82 & 0.85 & 2.54 & 2.4 & 3.12 \\
\hline$P$ & 0.001 & 0.22 & 0.75 & 0.001 & 0.001 & 0.32 & 0.01 & 0.001 \\
\hline
\end{tabular}

The beta weights in bold indicate individual linear regressions that explained $10 \%$ or more of the variance. The $P$ values indicate mean slopes that differed from a slope of zero using a significance criterion of either $P<0.001$ (bold) or $P<0.05$ (italic).

and increased again, the timing of the CRs remained relatively constant. The only large change occurred as the CR extinguished. The residual CRs occurred later and later, but nevertheless retained their duration. Thus, in terms of the balloon metaphor, the CR deflated asymmetrically as it merged with randomly distributed spontaneous movements (Kehoe et al. 1987, 2009). Then, in reacquisition, it reinflated rapidly. Whether or not the present results favoring the balloon metaphor would reappear at
ISIs other than the 500-msec value used here remains to be determined. For all ISIs, the basic spectral timing model would expect the magnitude and duration of CRs to expand in acquisition and contract in extinction although their peaks remain centered at the US locus.

An elegant feature of spectral timing models has been their ability to explain CR magnitude and timing by tying both of them to associative strengths attached to the microstimuli. 
Retaining this virtue while explaining the present results may be accomplished in a neurally realistic way by considering the cerebellar mechanisms that mediate eyeblink conditioning. The cerebellar pathways contain a sequence of plastic synapses in the cortex and the deep nuclei that drive the cranial nuclei for eyelid closure (Hesslow and Yeo 2002; Christian and Thompson 2003; Kalmbach et al. 2010; Lepora et al. 2010; Kalmbach and Mauk 2012). From a computational perspective, this sequence of plastic synapses forms a layered network that increases the flexibility of conditioning and its expression (Kehoe 1988; Medina et al. 2000a,b).

Why CR magnitude can change dramatically with little or no impact on timing may depend on this layered structure. Initial acquisition requires the facilitation of all the synapses in the sequence. Thus, timing can be established, perhaps very quickly, through the facilitation of the layer of Purkinje cells in the cerebellar cortex, but remains invisible until the deep nucleus layer is facilitated. In the Purkinje layer, there is induction of long-term potentiation (LTP) early in the CS-US interval versus induction of long-term depression (LTD) later in the CS-US interval. These changes in Purkinje cell activity regulate CR timing by suppressing the deep nuclei early in the interval and disinhibiting their responding later in the interval (Medina and Mauk 2000). Removing the LTP leads to a long-duration CR starting early in the CS-US interval (Perrett et al. 1993; Medina et al. 2000a; Kalmbach et al. 2010). Thus, underpinning the regulated time course of the CR is also a long-duration conditioned tendency for eyelid closure.

During the presentation of the CS-alone in extinction, LTP may progressively encroach on the LTD later in the CS, thus causing the progressive increase in the CR onset and CR peak before the entire CR disappeared. The increase in variability of the timing measures may reflect an unstable equilibrium between the increasing LTP and residual LTD. However, the variable increases in CR offset time are problematic for this possible account. At the risk of speculation, they may reflect late recruiting conditioned activity plus baseline activity unrelated to conditioning.

During changes in the cerebellar cortex during extinction, changes in synapses in the deep nuclei would remain largely intact (Perrett and Mauk 1995; Medina et al. 2002; Jirenhed et al. 2007; Kalmbach and Mauk 2012). This preserved conditioning would allow the original timing to be quickly recovered when the reintroduction of CS-US pairings in reacquisition training would cause the reinduction of LTD at the time of US presentation. Furthermore, the recruitment of additional granule-toPurkinje synapses could also capitalize on the preserved changes in the deep nuclei and produce the increased magnitude of CRs seen in reacquisition.

\section{Acknowledgments}

The authors thank the contributions of the original reviewers to the interpretation of the results. This experiment was approved under Australian ethics legislation. Preparation of this manuscript was supported by Alberta Ingenuity and the Informatics Circle of Research Excellence (iCORE) (to R.S.S.), both part of Alberta Innovates-Technology Futures (Canada).

\section{References}

Bird KD. 2004. Analysis of variance via confidence intervals. Sage, London. Buonomano DV, Mauk MD. 1994. Neural network model of the cerebellum: temporal discrimination and the timing of motor responses. Neural Comput 6: 38-55.

Christian KM, Thompson RF. 2003. Neural substrates of eyeblink conditioning: acquisition and retention. Learn Mem 11: 427-455.

Cohen J. 1988. Statistical power analysis for the behavioral sciences, 2nd ed. Erlbaum, Hillsdale, NJ.
Desmond JE, Moore JW. 1988. Adaptive timing in neural networks: the conditioned response. Biol Cybern 58: 405-415.

Gormezano I. 1966. Classical conditioning. In Experimental methods and instrumentation in psychology (ed. Sidowski JB), pp. 385-420. McGraw-Hill, New York.

Gormezano I, Kehoe EJ, Marshall BS. 1983. Twenty years of classical conditioning research with the rabbit. In Progress in psychobiology and physiological psychology (ed. Sprague JM, Epstein AN), Vol. 10, pp. 197-275. Academic Press, New York.

Grossberg S, Schmajuk NA. 1989. Neural dynamics of adaptive timing and temporal discrimination during associative learning. Neural Netw 2: 79-102.

Hesslow G, Yeo CH. 2002. The functional anatomy of skeletal conditioning. In A neuroscientist's guide to classical conditioning (ed. Moore JW), pp. 86-146. Springer, New York.

Hilgard E, Marquis D. 1935. Acquisition, extinction, and retention of conditioned lid responses to light in dogs. J Comp Psychol 19: $29-58$.

Hilgard ER, Marquis DG. 1936. Conditioned eyelid responses in monkeys, with a comparison of dog, monkey, and man. Psychol Monogr 47: $186-198$.

Hughes B, Schlosberg H. 1938. Conditioning in the white rat. IV. The conditioned lid reflex. J Exp Psychol 23: 641-650.

Jirenhed D-A, Hesslow G. 2011. Learning stimulus intervals—adaptive timing of conditioned Purkinje cell responses. Cerebellum 10: $523-535$.

Jirenhed D-A, Bengtsson F, Hesslow G. 2007. Acquisition, extinction, and reacquisition of a cerebellar cortical memory trace. J Neurosci 27: $2493-2502$.

Kalmbach BE, Mauk MD. 2012. Multiple sites of extinction for a single learned response. J Neurophysiol 107: 226-238.

Kalmbach BE, Davis T, Ohyama T, Riusech F, Nores WL, Mauk MD. 2010. Cerebellar cortex contributions to the expression and timing of conditioned eyelid responses. J Neurophysiol 103: 2039-2049.

Kalmbach BE, Voicu H, Ohyama T, Mauk MD. 2011. A subtraction mechanism of temporal coding in cerebellar cortex. J Neurosci 31: $2025-2034$.

Kehoe EJ. 1988. A layered network model of associative learning: learning-to-learn and configuration. Psychol Rev 95: $411-433$.

Kehoe EJ. 2006. Repeated acquisitions and extinctions in classical conditioning of the rabbit nictitating membrane responses. Learn Mem 13: $366-375$.

Kehoe EJ, Joscelyne A. 2005. Temporally specific extinction of conditioned responses in the rabbit (Oryctolagus cuniculus) nictitating membrane preparation. Behav Neurosci 119: 1011-1022.

Kehoe EJ, Schreurs BG. 1986. Compound-component differentiation as a function of CS-US interval and CS duration in the rabbit's nictitating membrane response. Anim Learn Behav 14: $144-154$.

Kehoe EJ, Marshall-Goodell B, Gormezano I. 1987. Differential conditioning of the rabbit's nictitating membrane response to serial compound stimuli. J Exp Psychol Anim Behav Process 13: $17-30$.

Kehoe EJ, Ludvig EA, Dudeney JE, Neufeld J, Sutton RS. 2008. Magnitude and timing of nictitating membrane movements during classical conditioning of the rabbit (Oryctolagus cuniculus). Behav Neurosci 122: $471-476$.

Kehoe EJ, Olsen KN, Ludvig EA, Sutton RS. 2009. Scalar timing varies with response magnitude in classical conditioning of the nictitating membrane response of the rabbit (Oryctolagus cuniculus). Behav Neurosci 123: $212-217$.

Lepora NF, Mavritsaki E, Porrill J, Yeo CH, Evinger C, Dean P. 2007. Evidence from retractor bulbi EMG for linearized motor control of conditioned nictitating membrane responses. J Neurophysiol 98: 2074-2088.

Lepora NF, Porrill J, Yeo CH, Evinger C, Dean P. 2009. Recruitment in retractor bulbi muscle during eyeblink conditioning: EMG analysis and common-drive model. J Neurophysiol 102: 2498-2513.

Lepora N, Porrill J, Yeo C, Dean P. 2010. Sensory prediction or motor control? Application of Marr-Albus type models of cerebellar function to classical conditioning. Front Comput Neurosci 4: 140.

Ludvig EA, Sutton RS, Kehoe EJ. 2012. Evaluating the TD model of classical conditioning. Learn Behav 40: 305-319.

Machado A. 1997. Learning the temporal dynamics of behavior. Psychol Rev 104: $241-265$.

Marshall-Goodell B, Schreurs BG, Gormezano I. 1982. Ruler vs. the Apple II/FIRST system analysis of analog signals in classical conditioning. Behav Res Methods Instrum 14: 519-525.

Mauk MD, Medina JF, Nores WL, Ohyama T. 2000. Cerebellar function: coordination, learning or timing? Curr Biol 10: R522-R525. 
Mavritsaki E, Lepora N, Porrill J, Yeo CH, Dean P. 2007. Response linearity determined by recruitment strategy in detailed model of nictitating membrane control. Biol Cybern 96: 39-57.

Medina JF, Mauk MD. 2000. Computer simulation of cerebellar information processing. Nat Neurosci 3: 1205-1211.

Medina JF, Garcia KS, Nores WL, Taylor NM, Mauk MD. 2000a. Timing mechanism in the cerebellum: testing predictions of a large-scale computer simulation. J Neurosci 20: 5516-5525.

Medina JF, Nores WL, Ohyama T, Mauk MD. 2000b. Mechanisms of cerebellar learning suggested by eyelid conditioning. Curr Opin Neurobiol 10: 717-724.

Medina JF, Nores WL, Mauk MD. 2002. Inhibition of climbing fibres is a signal for the extinction of conditioned eyelid responses. Nature 416: $330-333$.

Moore JW, Choi J-S. 1997. Conditioned response timing and integration in the cerebellum. Learn Mem 4: 116-129.

Napier RM, Macrae M, Kehoe EJ. 1992. Rapid reacquisition in conditioning of the rabbit's nictitating membrane response. J Exp Psychol Anim Behav Process 18: 182-192.

O'Brien RG, Kaiser MK. 1985. MANOVA method for analyzing repeated measures designs: an extensive primer. Psychol Bull 97: 316-333.
Ohyama T, Voicu H, Kalmbach B, Mauk MD. 2010. A decrementing form of plasticity apparent in cerebellar learning. J Neurosci 30: $16993-17003$.

Perrett SP, Mauk MD. 1995. Extinction of conditioned eyelid responses requires the anterior lobe of the cerebellar cortex. J Neurosci 15: 2074-2080.

Perrett SP, Ruiz BP, Mauk MD. 1993. Cerebellar cortex lesions disrupt learning-dependent timing of conditioned eyelid responses. J Neurosci 13: $1708-1718$.

Schneiderman N, Gormezano I. 1964. Conditioning of the nictitating membrane of the rabbit as a function of CS-US interval. J Comp Physiol Psychol 57: 188-195.

Smith MC. 1968. CS-US interval and US intensity in classical conditioning of the rabbit's nictitating membrane response. J Comp Physiol Psychol 66: $679-687$.

Vogel EH, Brandon SE, Wagner AR. 2003. Stimulus representation in SOP: II. An application to inhibition of delay. Behav Processes 62: $27-48$.

Received January 18, 2014; accepted in revised form July 15, 2014. 


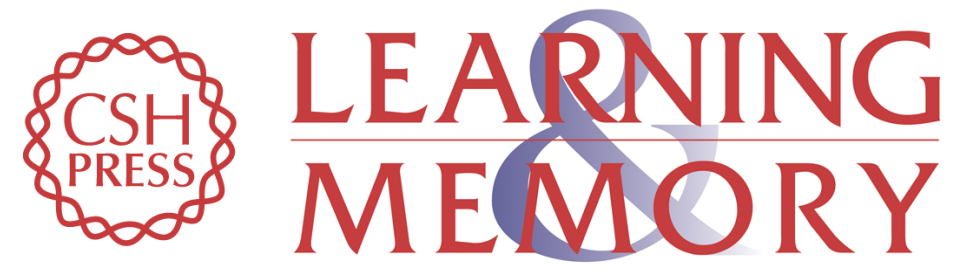

\section{Time course of the rabbit's conditioned nictitating membrane movements during acquisition, extinction, and reacquisition}

E. James Kehoe, Elliot A. Ludvig and Richard S. Sutton

Learn. Mem. 2014, 21:

Access the most recent version at doi:10.1101/Im.034504.114

References This article cites 41 articles, 8 of which can be accessed free at:

http://learnmem.cshlp.org/content/21/11/585.full.html\#ref-list-1

Creative This article is distributed exclusively by Cold Spring Harbor Laboratory Press for the

Commons

first 12 months after the full-issue publication date (see

License http://learnmem.cshlp.org/site/misc/terms.xhtml). After 12 months, it is available under a Creative Commons License (Attribution-NonCommercial 4.0 International), as described at http://creativecommons.org/licenses/by-nc/4.0/.

Email Alerting Receive free email alerts when new articles cite this article - sign up in the box at the Service top right corner of the article or click here. 